\title{
The Implications of Zambia's Draft Constitution for Maternal Mortality January 2015
}

In Zambia, induced abortion - 'termination of pregnancy' - is legal when carried out by a registered medical practitioner who believes that continuing a pregnancy involves a risk to the life of the pregnant woman, her physical or mental health or that of any of her existing children, greater than if the pregnancy were terminated; or who believes that a child born of the pregnancy would suffer from such physical or mental abnormalities as to be seriously handicapped. When forming their opinion of risk to health, medical practitioners may take account of the pregnant woman's actual or foreseeable environment and her age (The Termination of Pregnancy (ToP) Act 1972, revised 1994). In addition, the Penal Code Act was amended in 2005 to explicitly include rape or defilement of a female child as legal reason for inducing abortion and to exempt from prosecution female children who have attempted to self-abort in these circumstances (Articles 151 to 153).

However the drafting of the Zambian Constitution has caused confusion regarding the continuing validity of the ToP Act. Article 28 'Right to life' in all versions of the Draft Constitution states that a person has the right to life, beginning at conception. While the First Draft Constitution included a clause that made exception for the ending of life within the extent authorised by existing law (Article 28 Clause 2), such as the ToP Act, the Final Draft Constitution does not include the clause. In the Final Draft, the only exception given for the deprivation for life is a capital offence the sentence of which is death. It is not clear at this stage whether, if the Draft Constitution is accepted, the ToP Act, along with other laws, would therefore be subject to "modifications, adaptations, qualifications and exceptions as may be necessary to bring [it] into conformity with the Constitution." (The Constitution of Zambia Bill, 2014 p.5)

Regardless of its ultimate implications, the drafting of Article 28 is expected to exacerbate existing confusion, uncertainty and fear about ToP, and ultimately lead to an increase in unsafe abortion and subsequent maternal morbidity and mortality. It is estimated that unsafe abortion currently accounts for $30 \%$ of maternal deaths in Zambia $(\mathrm{MoH}, 2009)$, although this unsubstantiated figure is likely to underestimate the true extent of morbidity and mortality. Women, particularly poorer, younger women, resort to clandestine methods because of resources shortages, because of some health care providers' resistance to provide safe abortion services (Macha et al, 2014; Warenius et al. 2006), but most typically, because of limited awareness of how to obtain a safe, legal abortion (Coast, 2014; Koster-Oyekan, 1998).

Confusion regarding the current legislative framework exists both among the public and within the medical community. For example, a recent survey found that in both rural and urban areas, while the majority of young men and women thought that abortion was common or quite common in their community, the majority also believed abortion is never legal (BBC Media Action, 2014). In another recent study, women forced to seek hospital treatment following an unsafe abortion reported that they did not know that safe and legal services were available to them (Coast, 2014).

Among healthcare practitioners there is widespread misunderstanding of the protocols surrounding the provision of safe abortion. For example, the ToP Act specifies that the consent form must be signed by three medical practitioners, one of which must be an Obstetrics and Gynaecology 
specialist. However, in emergency situations, the ToP Act specifies that only one signature is needed. Many health professionals are unaware of the one signature requirement in emergency situations. To help medical providers interpret this legislative framework, the Ministry of Health has produced Standards and Guidelines for Reducing Unsafe Abortion Morbidity and Mortality (2009), but substantial lack of clarity still persists for many providers.

It is extremely unlikely that either increased perception of illegality or unavailability of safe abortion as a result of constitutional change (or discussion), or any eventual modification of the ToP Act to restrict abortion will curb the demand. Instead, given the high rates of unintended pregnancies (42\%) and high unmet need for contraception in Zambia (27\%) (CSO et al., 2009), girls and women are more likely to seek unsafe, clandestine terminations. In addition to the cost to these girls' and women's health and lives, the financial costs of treating the consequences of unsafe abortion will be substantial. It currently costs the Zambian public healthcare system more to treat the consequences of an unsafe abortion than it does to provide a safe and legal abortion (Vwalika, 2014).

Conversely, when made available and accessible, rates of safe abortion increase. This has occurred at Lusaka's University Teaching Hospital (UTH), where staff have been trained on the legality and importance of access to safe abortion. Between 2009 and 2011, over 5,000 women were admitted annually with an incomplete abortion or to request a safe termination. While the total number of cases did not change year on year, the proportion of safe, legal pregnancy terminations increased: from $3.2 \%$ in 2009 to $7.7 \%$ in 2011. This rise was even greater amongst adolescents, climbing from $2.5 \%$ to $15.4 \%$ (Macha et al., 2014). This evidence shows that it is possible to reduce unsafe abortions within a short time span. These improvements could be sustained and further amplified, across the country.

Many have spoken out against the constitutional change. These include the Zambian Medical Association, the Zambia Association of Obstetrics and Gynaecologists, individual practitioners and feminist activists (e.g. Longwe, 2012). Further, research suggests there may be considerable support in Zambia for protecting access to safe and legal abortion services, even when opposition to abortion on moral grounds is widespread (Geary et al., 2012).

\section{References}

- BBC Media Action (2014) 'Tikambe! (Let's Talk) Project Baseline'. BBC Media Action: Lusaka

- Central Statistical Office (CSO), Ministry of Health (MOH), Tropical Diseases Research Centre (TDRC), University of Zambia, and Macro International Inc. (2009) Zambia Demographic and Health Survey 2007.

- Coast, Ernestina (2014) 'Pregnancy termination trajectories in Zambia: causes and economic consequences' Presentation to Marie Stopes Zambia Workshop on the Prevalence and Impact of Abortion in Zambia Lusaka, 11 November 2014. Available from http://www.slideshare.net/ZambiaTOP/trajectories-to-safe-or-unsafe-abortion-in-zambia 
- Geary, Cynthia W, Gebreselassie, Hailemichael, Paschal, Awah and Pearson, Erin (2012) 'Attitudes toward abortion in Zambia', International Journal of Obstetrics and Gynaecology 118 Supplement 2, S148-151.

- Koster-Oyekan, Winny (1998) 'Why resort to illegal abortion in Zambia? Findings of a community-based study in Western Province', Social Science \& Medicine 46:10, 1303-1312.

- Longwe, Sara H. (2012) 'Gender comments on the first draft of the Zambian constitution 2012', AfricaWomenFirst blogpost

https://africanwomenfirst.wordpress.com/2012/08/02/gender-comments-on-the-draftzambian-constitution-2012/

- Macha, Swebby; Mayuni, Mutinta; Nkonde, Scholastic and Faundes, Anibal (2014) 'Increasing access to legal termination of pregnancy and postabortion contraception at the University Teaching Hospital, Lusaka, Zambia', International Journal of Gynaecology and Obstetrics 126, S49-51.

- Ministry of Health (2009) Standards and Guidelines for Reducing Unsafe Abortion Morbidity and Mortality (Lusaka: Government of the Republic of Zambia).

- Vwalika, B. (2014) "Costs and consequences of induced abortion in Zambia" Presented at the Zambia Medical Association AGM, Livingstone, Zambia, 8-9 August, 2014. Available from http://www.slideshare.net/ZambiaTOP/zambia-medical-association-2014

- Warenius, Linnéa U.; Faxelid, Elisabeth A.; Chishimba, Petronella N.; Musandu, Joyce O.; Ong'any, Antony A. and Nissen, Eva B-M (2006) 'Nurse-midwives attitudes to adolescent sexual and reproductive health needs in Kenya and Zambia', Reproductive Health Matters $14: 27,119-128$.

Briefing Paper prepared by Dr Ernestina Coast and Dr Emily Freeman with contributions from $\mathrm{Dr}$ Bellington Vwalika and Dr Alice Evans. Suggested citation Coast, E., Freeman, E., Vwalika B. \& Evans E. (2015) The Implications of Zambia's Draft Constitution for Maternal Mortality. Briefing paper prepared for the UK Department for International Development. London; Lusaka.

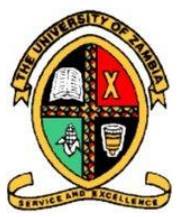

